\title{
PRÓLOGO AL DISCRETO LECTOR
}

El presente volumen ha surgido del deseo de colaboración e intercambio científico entre dos equipos universitarios de investigación, el Aula Biblioteca Mira de Amescua, de la Universidad de Granada, dirigida por el Dr. Agustín de la Granja, y el GRISO (Grupo de Investigación Siglo de Oro) de la Universidad de Navarra, dirigido por quien firma estas líneas e integrado en el Departamento de Literatura Medieval y del Siglo de Oro. A ambos nos complace agradecer a los responsables de la revista de Filología de la Universidad de Navarra, RILCE, su disponibilidad para acoger como número monográfico un conjunto de estudios que proceden en su mayor parte de las comunicaciones expuestas en el Coloquio miramescuano organizado por el Aula Biblioteca en Granada y diciembre de 1990. En ese coloquio me correspondió el honor de pronunciar la conferencia inaugural sobre los problemas de la edición de textos dramáticos, y pude participar en las reuniones del equipo granadino, en el que me integré más tarde como miembro extraordinario, de la misma forma que su director pertenece al GRISO en calidàd de asociado. La colaboración existente justifica que la prosigamos en el terreno de la publicación.

Por lo demás, en las dos Universidades estamos trabajando desde hace tiempo en las tareas de edición crítica y estudio de textos (particularmente dramáticos) del Siglo de Oro: las obras de Mira de Amescua en Granada, y las comedias de Tirso y autos sacramentales de Calderón en Navarra ${ }^{1}$. En el Preámbulo y en

1 Algunas ediciones realizadas en nuestro Departamento, y publicadas en diversas editoriales (colección de anejos de RILCE o en la de los Departamentos de literatura de la Universidad de Navarra, por ejemplo) demuestran bien la preocupación que veni- 
la primera ponencia, el Dr. de la Granja explica algunas de las ideas y propósitos relativos al trabajo que han emprendido para editar las obras completas de Mira de Amescua con el grado necesario de fiabilidad crítica. Por mi parte me complace que algunos de los criterios que sustentan este importante proyecto se hayan madurado en las discusiones mantenidas durante los dos Seminarios Internacionales sobre Edición y Anotación de textos del Siglo de Oro organizados por nuestro Departamento de Literatura Medieval y del Siglo de Oro en la Universidad de Navarra ${ }^{2}$, bajo la dirección del Dr. Jesús Cañedo y de mí mismo. Los contactos y discusiones en torno a esta área de las disciplinas filológicas vienen siendo, como se ve, continuos, y nuestros intercambios de experiencias editoriales prometen resultar beneficiosos para ambos equipos.

Por otro lado, el Consejo de Redacción de RILCE se había propuesto desde hace algún tiempo ampliar las perspectivas de la revista con la publicación de números monográficos. Esta parecía una oportunidad óptima: RILCE presenta, pues, un volumen monográfico que supone, creemos, una útil aportación a los estudios sobre Mira de Amescua, y sirve a la vez de órgano de difusión de un trabajo colectivo con el que miembros de la Universidad de Navarra y de la Universidad de Granada pretenden afirmar una colaboración simbiótica que redunde, en

mos manteniendo en este campo: recordaré solo algunos trabajos publicados (entre muchos otros que siguen inéditos en nuestra biblioteca): ediciones de Calderón, No hay burlas con el amor, Pamplona, Eunsa, 1981 (ed. de I. Arellano); Tirso de Molina, Esto si que es negociar, Pamplona, Eunsa, 1985 (ed. de V. García Ruiz); Calderón, El agua mansa. Guárdate del agua mansa, Kassel, Reichenberger, 1989 (ed. de I. Arellano y V. García Ruiz); Calderón, El escondido y la tapada, Barcelona, PPU, 1988 (ed. de M. Larrañaga); Lope de Vega y Monteser, El caballero de Olmedo, Pamplona, Eunsa, anejos de RILCE, 1991 (ed. C. C. García Valdés); Bances Candamo, Cómo se curan los celos, Pamplona-Ottawa, Eunsa-Dovehouse editions, 1991 (ed. I. Arellano), etc.

2 El primero se celebró en diciembre de 1986, y el segundo en abril de 1990. Las actas de los dos han sido publicadas por I. Arellano y J. Cañedo: Edición y anotación de textos del Siglo de Oro, Pamplona, Eunsa, 1987, y Crítica textual y anotación filológica. Siglo de Oro, Madrid, Castalia, 1991 (en prensa y a punto de salir cuando escribo estas líneas). 
última instancia, en la mejora del panorama crítico de los textos teatrales del Siglo de Oro, tan necesitados de una atención sistemática y sin pausa.

Mucho camino queda por recorrer. Útil y agradable será recorrer algunos trechos en tan amistosa compañía*.

Ignacio Arellano

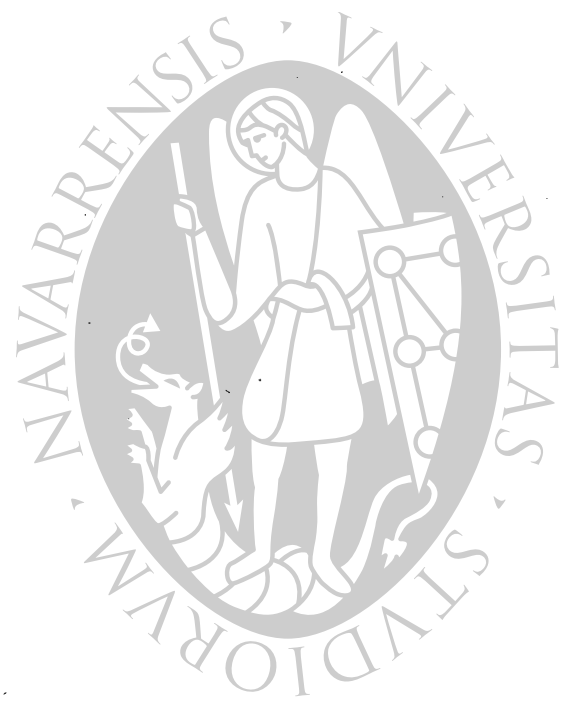

* Nota: Sobre la paginación de este volumen reparará el lector en que comienza en la 169, lo que obedece a la circunstancia de ser éste el segundo fascículo del volumen séptimo de $R I L C E$, por lo que continúa la paginación desde el primero. 